\title{
More Than Brides Alliance: Baseline report, Niger
}

Grace Saul

Andrea J. Melnikas

Population Council

Sajeda Amin

Population Council

Sarah Engebretsen

Aissa Diarra

See next page for additional authors

Follow this and additional works at: https://knowledgecommons.popcouncil.org/departments_sbsr-pgy

Part of the Demography, Population, and Ecology Commons, Family, Life Course, and Society Commons, International Public Health Commons, and the Maternal and Child Health Commons How does access to this work benefit you? Let us know!

\section{Recommended Citation}

Saul, Grace, Andrea J. Melnikas, Sajeda Amin, Sarah Engebretsen, Aissa Diarra, and Chaibou Saadou. 2017. "More Than Brides Alliance: Baseline report, Niger." New York: Population Council. 


\section{Authors}

Grace Saul, Andrea J. Melnikas, Sajeda Amin, Sarah Engebretsen, Aissa Diarra, and Chaibou Saadou 


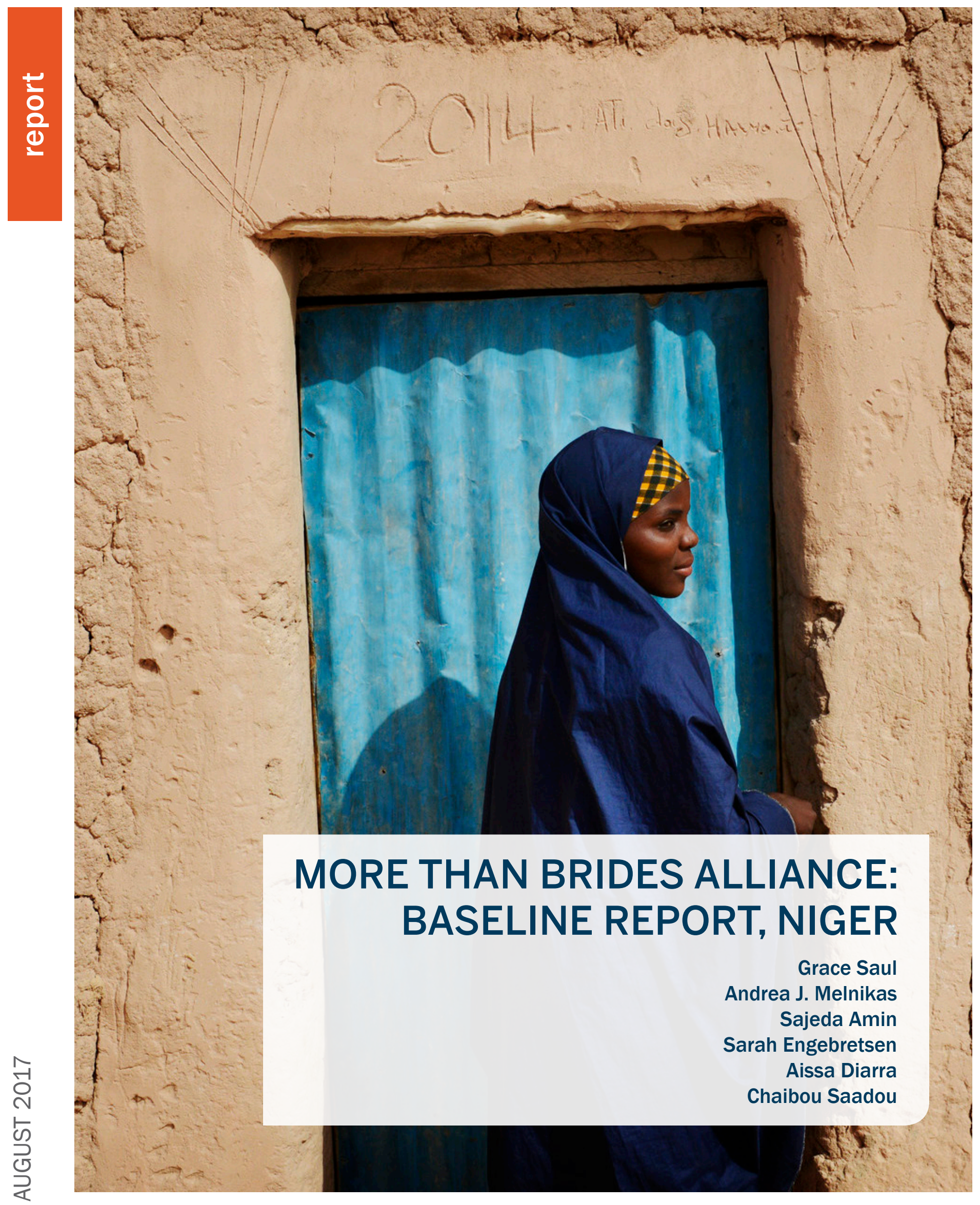

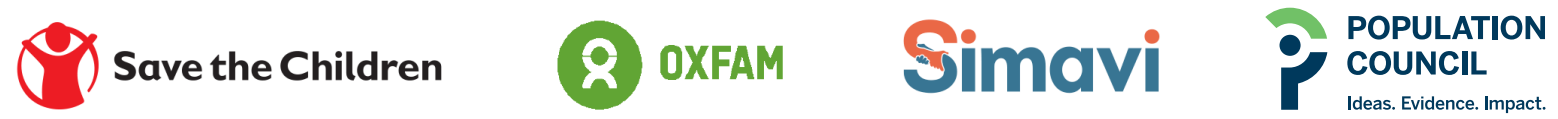




\section{Population
council \\ Ideas. Evidence. Impact.}

The Population Council confronts critical health and development issues-from stopping the spread of HIV to improving reproductive health and ensuring that young people lead full and productive lives. Through biomedical, social science, and public health research in 50 countries, we work with our partners to deliver solutions that lead to more effective policies, programs, and technologies that improve lives around the world. Established in 1952 and headquartered in New York, the Council is a nongovernmental, nonprofit organization governed by an international board of trustees.

\section{Population Council}

1 Dag Hammarskjold Plaza

New York, NY 10017

USA

Tel: +12123390500

Fax: +12127556052

email: pubinfo@popcouncil.org

popcouncil.org

Suggested citation: Saul, Grace, Andrea J. Melnikas, Sajeda Amin, Sarah Engebretsen, Aissa Diarra, and Chaibou Saadou. 2017. “More Than Brides Alliance: Baseline Report, Niger.” New York: Population Council.

Photo credit: Oxfam Novib

The More Than Brides Alliance Baseline Reports are available for India, Malawi, Mali, Niger.

(C) 2017 The Population Council, Inc. 


\section{Table of Contents}

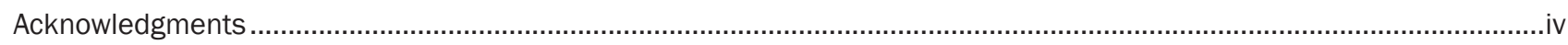

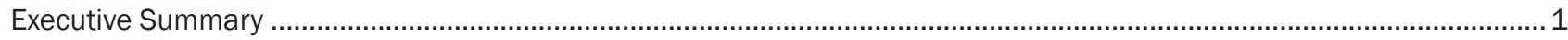

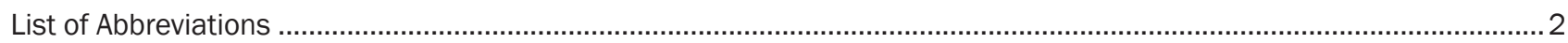

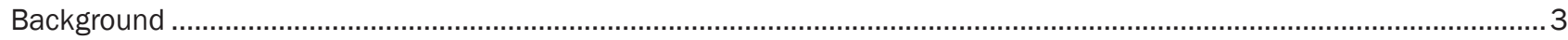

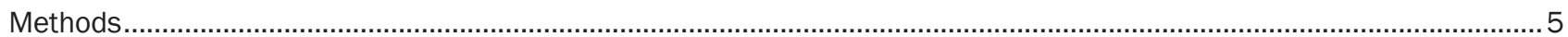

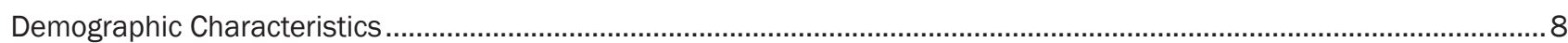

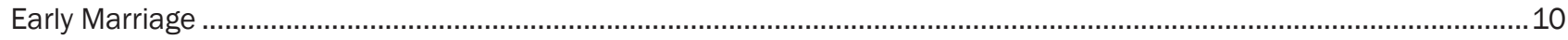

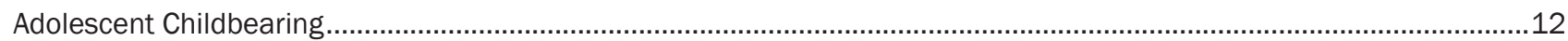

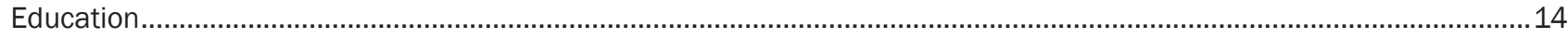

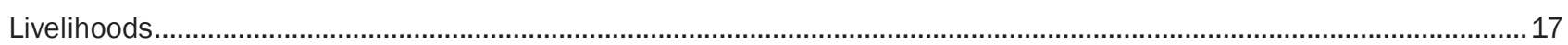

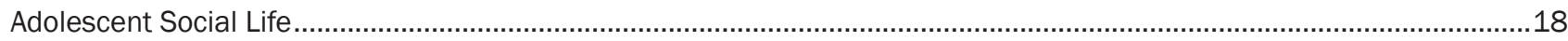

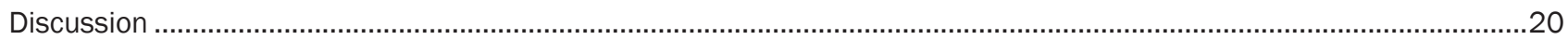

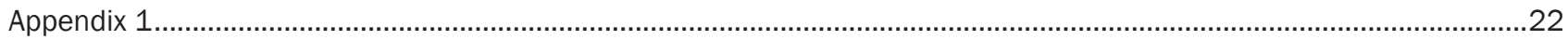

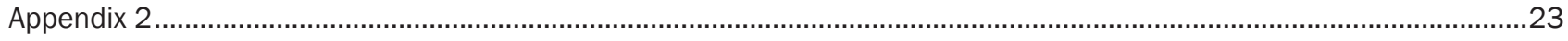

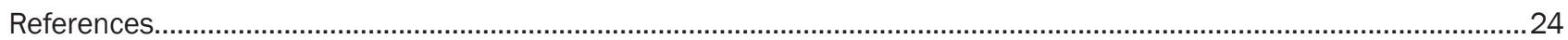




\section{Acknowledgments}

A number of individuals have contributed to the baseline report for Niger and we appreciate their efforts.

We thank the members of the More Than Brides Alliance, including Save the Children Netherlands, Oxfam Novib, and Simavi. In Niger, Save the Children Netherlands and Oxfam Novib are implementing programs to delay marriage and improve outcomes for adolescent girls in cooperation with local partners FASSALI, MUNGANE, SONGES, SOS, and ANBEF. We look forward to seeing the results from these interventions.

We also thank the Ministry of Foreign Affairs Netherlands for their support of the More Than Brides Alliance and of the research and evaluation component specifically.

At LASDEL we would like to thank our colleagues who oversaw data collection in the field, including Ali Bako. We have been fortunate to work with a talented team that was instrumental in conducting the household listing and baseline survey with adolescent girls and young women.

Finally, we are grateful for the research participants, and in particular the adolescent girls and young women who shared their experiences, thoughts, and ambitions with the research team. We thank them for their participation, without which this report would not be possible. 


\section{Executive Summary}

We conducted baseline surveys of adolescents in select areas of two regions in Niger (Tillaberi and Maradi) as part of an evaluation of interventions to delay marriage. The goals of the baseline were to: 1) provide a benchmark against which changes resulting from the intervention may be measured at the midline and endline periods; 2 ) provide information about the current situation and context for adolescent girls in select areas in Niger in order to inform the intervention; and 3) identify themes in need of further exploration through qualitative research. The baseline survey was carried out in partnership with a local research group based in Niamey (Laboratoire d'Etudes et de Recherche sur les Dynamiques Sociales et le Developpement Local)

(LASDEL). Baseline data collection included a household listing $(n=2,949)$ that included data on females aged 10-21 living in the household, and baseline surveys of female adolescents and young women aged 12-19 $(n=600)$ that collected information on marital status and history, education, sexual and reproductive health knowledge and experience, learning outcomes, migration history, livelihoods, and social connections. Surveys were carried out in intervention villages $(n=15)$ and comparison villages $(n=15)$ that were assigned based on criteria set by the program.

Our sample included 401 girls in Tillaberi and 199 in Maradi, with a mean age of 15.2 years (Tillaberi) and 15.0 years (Maradi). Overall, more than half of females aged 15-19 in our sample (52.4\%) reported ever being married. In Tillaberi, $41.0 \%$ of females aged 15-19 reported ever being married and in Maradi it was much higher at $77.9 \%$. Very early marriage (before age 15 ) was also high: $28.9 \%$ of females aged 15-19 in Tillaberi reported being married by age 15 and in Maradi it was 61.5\%

Childbearing in our sample occurred within marriage, with almost no exception: Among never-married girls over the age of $15(n=160)$, only $1(0.6 \%)$ reported ever being pregnant. Among ever-married girls over the age of 15, 25.7\% reported ever being pregnant, with $18.8 \%$ of those respondents pregnant at the time of the survey.

Data on enrollment in school suggested that enrollment rates are low among all adolescent females aged 12-19, but among those that ever attended school, early marriage appears to mark the end of formal education for many. Overall enrollment rates start to drop around age 14, culminating in $82.0 \%$ of 19 -year-olds not enrolled in school. Examining these data by region, we find that the proportion not enrolled in school is consistently higher in Maradi compared to Tillaberi (overall $48.6 \%$ of those in Tillaberi are not in school compared to $85.4 \%$ in Maradi). In Maradi, no girls in our sample were in school after age 16, and by age 14 only $84.4 \%$ were still in school.

We found that few girls were already engaged in incomegenerating activities: only $15.8 \%$ of respondents aged 12-19 reported ever working to earn money. Among those who reported ever working ( $n=95), 47.4 \%$ were currently working, with a higher proportion in Tillaberi currently working (58.7\%) compared to Maradi (25.0\%).

The More Than Brides Alliance seeks to improve the lives of adolescent girls and includes activities across multiple domains (reproductive health, education, gender norms, and livelihoods, to name a few). Our findings suggest that girls in these communities in Tillaberi and Maradi have a demonstrated need for interventions to address these vulnerabilities. Findings from the baseline study will be used both to evaluate changes over time that may be attributable to the MTBA intervention and to inform programmatic staff seeking to understand the populations they are serving. 


\title{
List of Abbreviations
}

\author{
DHS Demographic and Health Survey \\ EA Enumeration Area \\ LASDEL Laboratoire d'Etudes et de Recherche sur les Dynamiques Sociales et le Developpement Local \\ LSE Life Skills Education \\ MTBA More Than Brides Alliance \\ SRHR Sexual and Reproductive Health and Rights
}




\section{Background}

Niger has one of the highest rates of early marriage globally, with $76.3 \%$ of girls married by age 18 and $28.0 \%$ by age 15 (DHS 2012). Using data from the Demographic and Health Surveys (DHS), Figure 1 shows proportions of women married by age among the different regions in Niger. These rates are accompanied by high total fertility ( 7.6 births per woman), rates of adolescent childbearing (209 births per 1,000 females aged 15-19), maternal mortality (630 deaths per 100,000 live births), and infant mortality (59.9 per 1,000 live births) (World Bank 2017). These rates suggest that Niger is among countries with the poorest health indicators. While age at marriage has increased over the past few decades in some West African contexts, such as in Mauritania, Togo, Benin, and Burkina Faso, the rates of child marriage and adolescent childbearing in Niger have remained very high and essentially unchanged (Fenn et al. 2015). Niger also has the world's fastest-growing population-at a rate of $3.3 \%$ per year.

Some studies have argued that in rural West and Central Africa, child marriage may be practiced as a response to extreme poverty faced by families. By arranging for their daughters to marry young, parents are relieved of the economic burden of providing for additional children. Furthermore, daughters may be seen as a source of revenue, as according to tradition, husbands are expected to pay dowry. In Niger, younger brides attract higher dowries (Ensminger and Knight 1997; Mathur et al. 2003). While such exchanges may provide temporary financial relief for families, child marriage has detrimental effects over the long term, both with respect to social and economic development. Child marriage may perpetuate poverty from one generation to the next, because women married as girls often do not possess the knowledge and skills needed to contribute financially to their households and to invest in the health and education of their children (Walker 2012).

While poverty is a known driver of child marriage, Malhotra and colleagues (2011) and Fenn and colleagues (2015) found that child-marriage risk was not significantly different among the bottom 80 percent of households; only the top 20 percent demonstrated significantly lower rates of child marriage. It is unclear whether this is because of the
The More Than Brides Alliance implements and evaluates the effectiveness of a range of interventions to delay child marriage, including education, economic opportunities, child promotion, SRHR services, community engagement, and others. In Mali and Niger, the Council is conducting a quasiexperimental matched study, and in India and Malawi a cluster randomized trial to evaluate whether and to what extent these child marriage interventions improve young people's ability to decide when to marry and pursue their sexual and reproductive health rights in a supportive environment.

FIGURE 1. Percent of women aged 20-24 married, by age (DHS 2012)

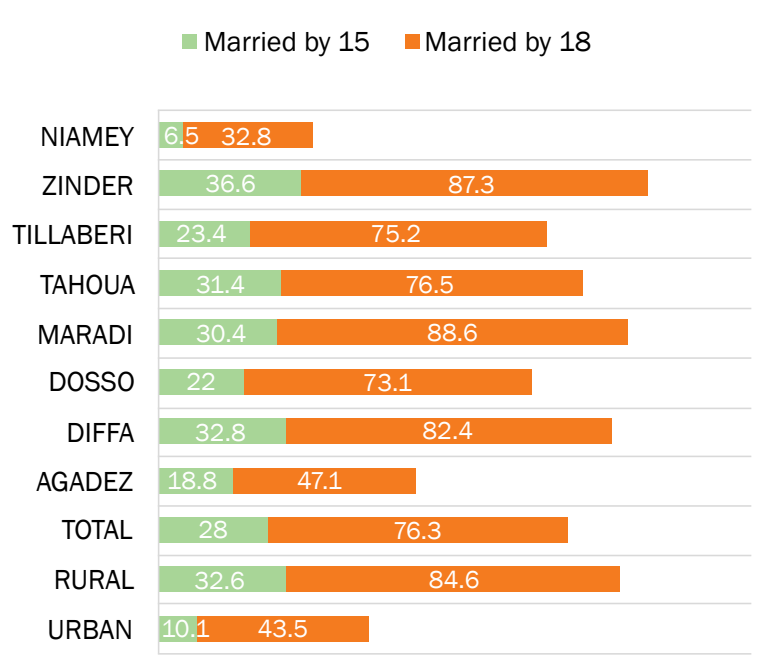

strength of the social norms upholding the practice even in relatively well-off segments of the population, or if it is merely the reflection of a relatively small variation in absolute wealth among groups.

Data from the DHS show that the education level is extremely low in Niger. According to the DHS, among females 10-14 years of age, $70.2 \%$ are not in school. In rural areas, $77 \%$ are not in school. Males fare only slightly better: nationally, $55.6 \%$ are not in school, and in rural areas this increases to $60.9 \%$. By age $15-19$ these numbers are even 
higher. Almost all females aged 15-19 from rural areas are not in school (97.2\%), and 9 out of 10 females aged 15-19 are not in school (90\%).

\section{Intervention}

The More Than Brides Alliance (MTBA) is a program implemented by Save the Children International, Oxfam Novib, and Simavi that aims to improve outcomes for adolescent girls in five countries: India, Malawi, Mali, Niger, and Pakistan. Broadly, the MTBA programs have defined five key result areas:

- Empowering at-risk and already-married adolescents, girls in particular, with life skills education (LSE), comprehensive sexuality education (CSE), and sexual and reproductive health and rights (SRHR) information;

- $\quad$ Providing alternatives to child marriage and mitigating the impact on married girls, through enhancing access to education, economic opportunities, and child protection systems for girls and their families;

- Increasing access to SRHR services for young people;

- $\quad$ Changing social norms;

- Influencing legal and policy frameworks.

In Niger, the MTBA is being implemented in Maradi and Tillaberi regions by Save the Children and Oxfam Novib, respectively, in cooperation with local NGOs: FASSALI, MUNGANE, SONGES, SOS, and ANBEF. As the research and learning agenda partner of the MTBA, the Population Council is evaluating interventions in India, Malawi, Mali, and Niger.

\section{Study Aims}

The aims of this baseline study were to: 1 ) provide a benchmark against which changes resulting from the MTBA intervention may be measured at the midline and endline periods; 2) provide information about the current situation and context for adolescent girls in select areas in Niger in order to inform the MTBA intervention; and 3) identify themes in need of further exploration through qualitative research. 


\section{Methods}

The baseline research included the following data collection components:

- Household listing of select intervention and comparison villages with collection of key outcome indicators for females aged 10-21, including marital status, school enrollment, childbearing status, and work status

- Baseline survey of females aged 12-19 in select intervention and comparison communities. Categories of questions included:

- Background characteristics

- Migration

- Education and Schooling Experience including Literacy and Numeracy Evaluation

- Reproductive Health Knowledge

- Marriage and Dowry

- Sexual Experience

- Mobility

- Social Context

- Gender Equality

- $\quad$ Livelihoods

The MTBA seeks to improve the lives of adolescent girls, including increasing school enrollment and educational attainment, improving reproductive health outcomes, and empowering girls to have more agency in decisions about their lives, including marriage. Primary outcomes of interest include indicators such as proportion married before age 18 , proportion pregnant before age 18 , and proportion in school. Many of the domains included in the survey are directly related to these outcomes (e.g., questions about age at first marriage), while others are less direct but still influence the pathway (e.g., migration may make girls more or less vulnerable to negative outcomes depending on the circumstances surrounding the migration). We collect data
FIGURE 2. Areas included in the baseline research

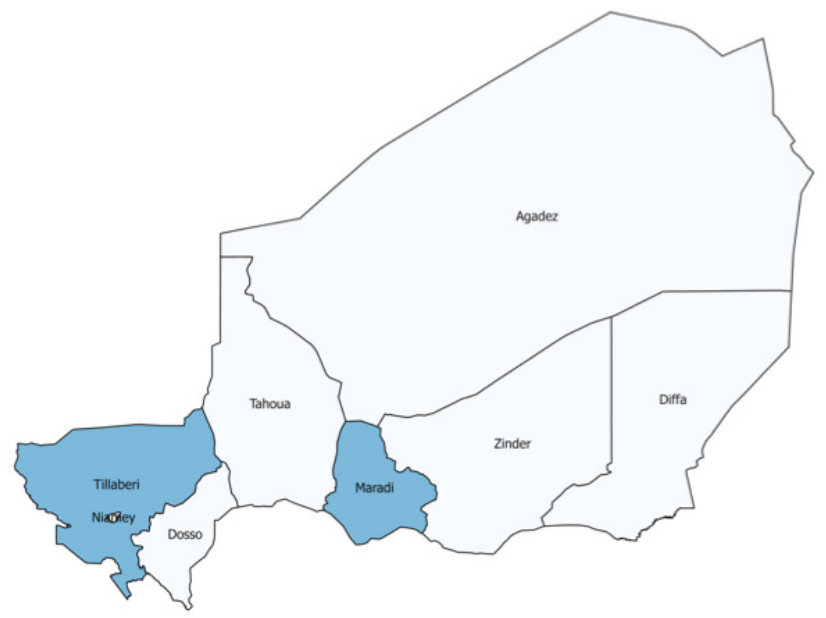

on indicators that help us measure program impact as well as help us better understand the context and constraints around key outcomes in order to inform program design and delivery.

The study was implemented in Maradi and Tillaberi regions of Niger by the Laboratoire d'Etudes et de Recherche sur les Dynamiques Sociales et le Développement Local (LASDEL) based in Niamey. Figure 2 shows the locations for the baseline data collection. Both regions are in southern Niger, with relatively high population densities and road networks. ${ }^{1}$

Ethical review: Ethical and research clearance for this study was issued by the Institutional Review Board of the Population Council.

Sample size: We conducted sample size estimations using Optimal Design, assuming that half of the data collection areas would be designated as comparison areas. Calculations and our assumptions are included in Appendix 1. Based on a target sample size of 600 girls (30 clusters of 20 girls each) we estimate a minimum detectable effect size for the outcome of proportion of females aged 12-19 married at endline.

\footnotetext{
${ }^{1}$ https://ij-healthgeographics.biomedcentral.com/articles/10.1186/1476-072X-11-24
} 
Trial design: We used a quasi-experimental ${ }^{2}$ design selecting intervention and comparison areas on key indicators as provided by implementing partners. Due to program implementation plans we were not able to conduct a cluster randomized design.

\section{Data Collection}

\section{Site Selection}

Intervention areas: Intervention villages for the MTBA program were selected by the implementing partners (Save the Children and Oxfam Novib). Selection criteria included:

1. Existence of school infrastructure (primary and secondary school);

2. Population size and estimated number of adolescents; ${ }^{3}$

3. Accessibility during all seasons of the year;

4. Previously implemented child marriage intervention that was a precursor to MTBA; ${ }^{4}$

5. Absence of other child-marriage interventions;

6. Presence of two ethnic groups.

From this list of intervention villages selected for the MTBA program $(n=42)$, we randomly selected 15 villages to serve as intervention villages for the baseline survey. Note that of the 42 intervention villages, 32 are served by Oxfam Novib and located in Tillaberi and 10 are served by Save the Children and located in Maradi.

Comparison areas: Because the selection of intervention villages was so specific, we aimed to select comparison areas that met as many of the intervention selection criteria as possible. We asked implementing partners to provide a list of villages within the same districts as the intervention villages that met the selection criteria for intervention villages. Note that not all selection criteria could be met; for example, we do not have comparison villages that previously implemented the child-marriage intervention that was a precursor to MTBA. From the list of suitable comparison areas provided by the partners $(n=813)$, we removed villages with populations too large or small to be comparable to intervention villages $(n=598)$ based on the population size of intervention villages (between 466 and 2,000). We then randomly selected 15 villages to serve as comparison villages from the remaining villages $(n=215)$.

Enumeration areas: Although we randomized at the village level, to standardize data collection we selected enumeration areas ${ }^{5}$ to serve as the boundaries for the collection of the household listing data. Enumeration areas, including maps of these areas, were acquired from the Institut National de la Statistique (INS-Niger) in Niamey. For selected villages with more than one enumeration area, we randomly selected one enumeration area to be included in the baseline data collection. Once selected, all households within that enumeration area were visited and data on females aged 10-21 living in that household were collected from an adult household member.

Participants: All households within the selected enumeration area were eligible for inclusion in the study. If the household reported no adolescent females aged 10-21, the listing was quite short. From the household listing frame, we randomly selected households with females aged 12-19 years of age for participation in the baseline survey using a Kish grid. Only one female per household was selected for inclusion in the baseline survey.

\section{Household Listing and Baseline Survey}

In January 2017, the household listing and household survey data collection were carried out in select communities in Maradi and Tillaberi. Female enumerators were selected from a roster of enumerators with previous experience working with LASDEL. Fifteen female enumerators were selected for their experience working on surveys with adolescents and/or surveys with sensitive topics. Training took place in Niamey from January 9-12, 2017. Data collection enumerators participated in a four-day training session that included background information about the project, study goals and objectives, the content of the household listing and baseline survey tools, data entry, and research ethics and participant protection. Pretesting of the tools was conducted during the training. Two survey teams (Maradi) and four survey teams (Tillaberi) were created with one team leader and three interviewers each.

\footnotetext{
${ }^{2}$ In quasi-experimental designs, treatment is not randomly assigned. By contrast, in experimental designs where treatment is randomized, it is assumed that intervention and comparison groups are similar at baseline.

${ }^{3}$ Intervention areas had a population size of at least 466 but not more than 2,000.

${ }^{4}$ The program My Rights My Voice was implemented in multiple countries including Mali. More information is available at: http://policy-practice.oxfam.org.uk/our-work/youth/youth-participation/my-rights-my-voice.

${ }^{5}$ Enumeration areas are geographic areas specified by the Census.
} 
Enumerators trained by LASDEL conducted the data collection in tandem, first conducting the household listing in select enumeration areas $(n=30 ; 15$ intervention and 15 comparison) and then randomly selecting participants ( $n=20$ per enumeration area) for the baseline survey from the household listing. All data from the household listing were captured electronically using mobile phones. The baseline survey was also completed electronically. A total of 2,949 households were listed and a total of 600 baseline questionnaires were completed.

Individual written informed consent was obtained from all participants prior to conducting the interviews. For adolescents under age 18, parental permission was first obtained before obtaining adolescent assent.

Data for key indicators (proportion married, proportion who had begun childbearing, proportion in school) were collected in both the household listing and baseline survey instruments. Data from the household listing were collected from the head of household or another adult in the household about females aged 10-21 living in the household, thus data from the household listing may be subject to bias. Data from the baseline survey were collected directly from female respondents aged 12-19.

\section{Data Analysis}

Data were entered directly into SurveyCTO via a mobile app and uploaded to a secure server. Data were downloaded into STATA 14.1 for cleaning and analysis. Data analysis primarily focused on descriptive statistics for variables of interest. Although the analysis focuses on comparisons between regions, we include a table in Appendix 2 comparing intervention and comparison areas on key indicators. 


\section{Demographic Characteristics}

Table 1 shows key demographic characteristics for the sample, by region. We found that Tillaberi and Maradi were quite dissimilar in these indicators. Most relevant for our purposes, the proportion married was higher in Maradi (40.7\%) compared to Tillaberi (25.7\%). We also found that the Tillaberi sample was wealthier, with a much higher proportion of respondents in the lowest quintile in Maradi (45.2\%) than Tillaberi (10.0\%). The overwhelming majority of mothers and fathers of the sample respondents had no education in both regions. Respondents in Tillaberi were more likely to own an ID card and come from smaller families: on average, respondents had 5.1 siblings in Tillaberi compared to 6.6 in Maradi. Respondents from Tillaberi appeared to be more mobile: $72.3 \%$ reported they always lived in the village, compared to $83.4 \%$ in Maradi.

Figure 3 shows the age distribution of respondents in the baseline survey. The higher proportion of girls age 12 and 13 and lower proportion of girls age 19 may be due to age heaping, with respondents seeking to be eligible for the survey and reporting an older age, or conversely reporting an older age to be excluded from the survey. Such patterns of age heaping are common in populations where age is not known and has to be estimated. The large number of girls age $13(n=144 ; 24 \%$ of the total sample) may skew the data somewhat as they are less likely to be married and more likely to be enrolled in school. Overall, the mean age of respondents was 15.2 in Tillaberi and 15.0 in Maradi.

Previous research in Niger suggests that early marriage is more common among certain ethnic groups; those identifying as Tuareg are more likely to practice early marriage compared to those identifying as Hausa (Fenn et al. 2015). We examined ethnicity in our sample to understand how it may influence early marriage. Overall, the most commonly reported ethnicities were Fulani (28.5\%), Hausa (27.5\%), and other ${ }^{6}$ (20.2\%). In Tillaberi, the most common ethnicities were Fulani (32.4\%), other ${ }^{7}$ (30.2\%), and Zarma Songhay $(28.2 \%)$, while in Maradi the most common ethnicities were Hausa (70.8\%), Fulani (20.6\%), and Tuareg (7.0\%). This suggests that our sample may not include the ethnic groups with the highest proportion of girls marrying early and thus may explain lower overall marriage rates in our sample compared to national data for Niger.

TABLE 1. Key demographic indicators, by region $(n=600)$

\begin{tabular}{|l|c|c|}
\hline & Tillaberi & Maradi \\
\hline & $\mathrm{N}=401$ & $\mathrm{~N}=199$ \\
\hline Age (mean) & 15.2 & 40.0 \\
\hline Respondents who were currently married (\%) & 25.7 & 14.7 \\
\hline Age at marriage (mean) & 15.1 & 87.1 \\
\hline Parental education & & 77.7 \\
\hline Mother has no formal schooling (\%) & 83.4 & 6.2 \\
\hline Father has no formal schooling (\%) & 74.5 & 1.5 \\
\hline Has a national ID card & 46.9 & 6.6 \\
\hline Is non-Muslim (\%) & 11.7 & 45.2 \\
\hline Number of siblings (mean) & 5.1 & 83.4 \\
\hline Lowest wealth quintile (\%) & 10.0 & \\
\hline Has always lived in that village (\%) & 72.3 & \\
\hline
\end{tabular}

\footnotetext{
${ }^{6}$ In the baseline we did not ask specifics about what other ethnicity but may revisit this at midline.

${ }^{7}$ We do not have exact numbers, but LASDEL notes that "other" was frequently Gurma.
} 
FIGURE 3. Total number of respondents, by age and region

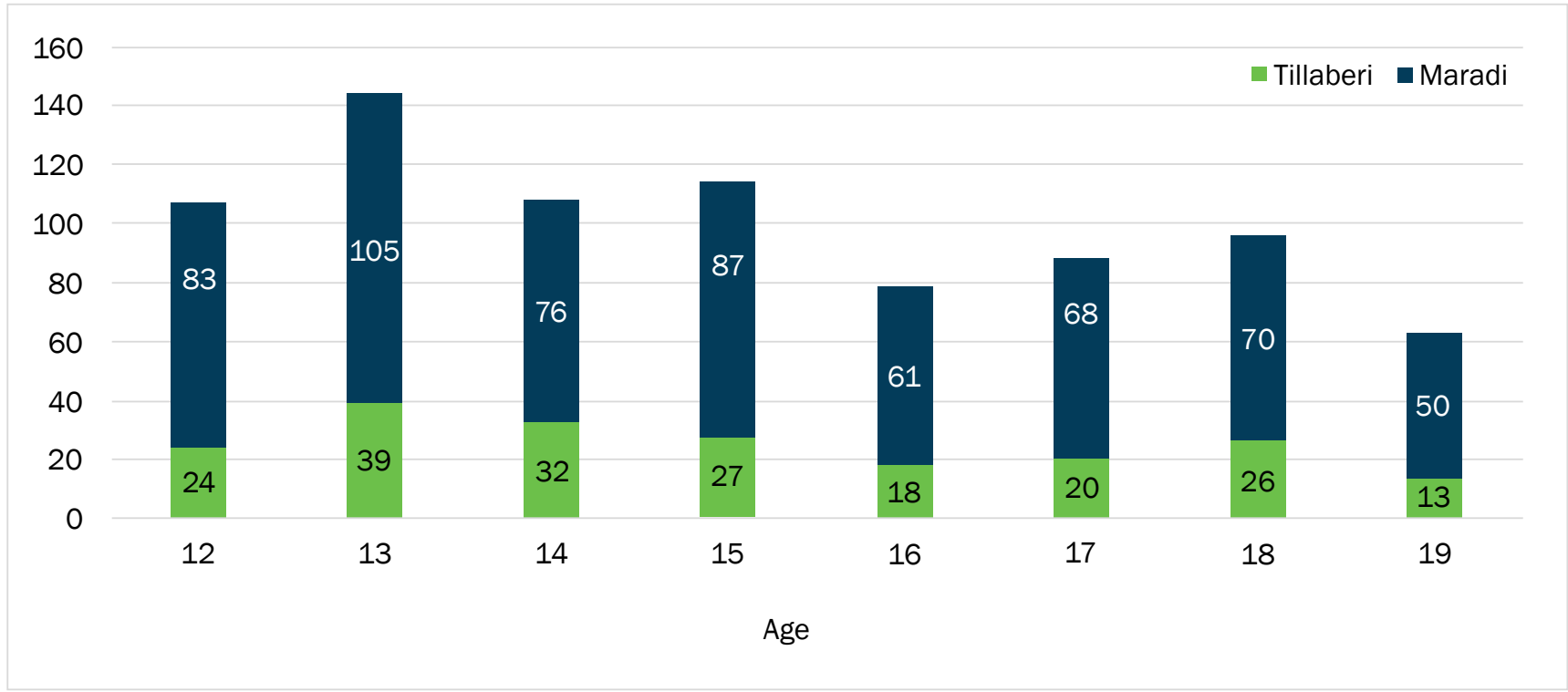




\section{Early Marriage}

Overall, more than half of females aged 15-19 in our sample (52.4\%) reported ever being married. In Tillaberi, $41.0 \%$ of females aged 15-19 reported ever being married, and in Maradi it was much higher at $77.9 \%$. Among the entire sample (aged 12-19), 30.8\% were ever married; in Tillaberi $25.9 \%$ were ever married compared to $40.7 \%$ in Maradi. Very early marriage (before age 15 ) was also high: $28.9 \%$ of females aged 15-19 in Tillaberi reported being married by age 15 and in Maradi it was 61.5\%. Figure 4 shows proportions married by age overall and by region, suggesting that the proportion of girls married begins to accelerate at age 14 , and by age 19 all girls in Maradi and two-thirds of girls in Tillaberi (67.6\%) report ever being married.

In Table 2, we examine key outcome indicators for early marriage. We include contextual indicators, such as proportion in polygamous unions (12.6\% in Tillaberi and $32.1 \%$ in Maradi) and mean age difference with spouse to provide insight into the kinds of marriages young girls enter into in Niger. Among those married, the mean age difference between partners was 8.8 years. There were slight differences between the regions, with a mean age difference of 8.7 years in Tillaberi and 9.0 years in Maradi. More girls were in polygamous unions in Maradi (32.1\%), and the majority of those in polygamous unions (84.6\%) were the second wife.
KEY FINDING

$524 \%$ Proportion of girls aged 15-19 ever married (overall sample)

We speculate that higher rates of polygamy may be related to higher proportion married $(40.7 \%$ in Maradi compared to $25.7 \%$ in Tillaberi) and the younger age at first marriage (14.7 years in Maradi compared to 15.1 years in Tillaberi).

FIGURE 4. Proportion ever married, by age

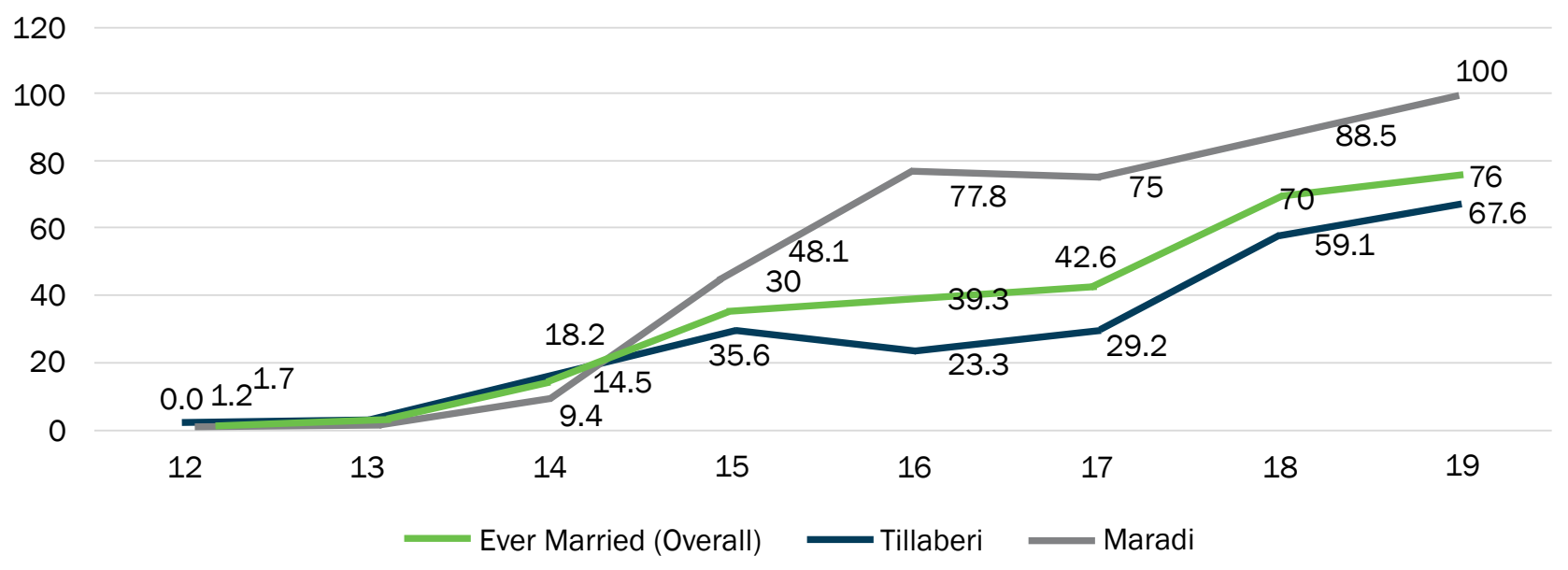


TABLE 2. Key indicators related to marriage, girls aged $12-19$, by region $(n=600)$

\begin{tabular}{|l|c|c|}
\hline & Tillaberi & Maradi \\
\hline & $\mathrm{N}=401$ & N=199 \\
\hline Currently married (\%) & 25.7 & 40.7 \\
\hline Ever married (\%) & 26.4 & 32.2 \\
\hline In polygamous union (among married) (\%) & 12.6 & 9.0 \\
\hline $\begin{array}{l}\text { Mean age difference w/spouse (among } \\
\text { married) (years) }\end{array}$ & 8.7 & 14.7 \\
\hline Mean age at first marriage (years) & 15.1 & 2 \\
\hline
\end{tabular}

TABLE 3. Knowledge related to early marriage, girls aged $12-19$, by region $(n=600)$

\begin{tabular}{|l|c|c|c|}
\hline & Tillaberi & Maradi & Overall \\
\hline $\begin{array}{l}\text { Girls who can correctly identify the legal } \\
\text { age at marriage for girls in Niger (15) (\%) }\end{array}$ & 18.0 & 44.1 & 28.3 \\
\hline $\begin{array}{l}\text { Girls who can name at least three } \\
\text { adverse effects of early marriage (\%) }\end{array}$ & 21.4 & 8.5 & 17.2 \\
\hline
\end{tabular}




\section{Adolescent Childbearing}

We asked respondents age 15 and older $(n=336)$ about their pregnancy experiences. We found almost no reported instances of pregnancy outside of wedlock: among nevermarried girls over 15 ( $n=160)$, only $1(0.6 \%)$ reported ever being pregnant. Among ever-married girls over 15, 25.7\% reported ever being pregnant, with $18.8 \%$ of those respondents pregnant at the time of the survey.

Among those who had ever given birth $(n=38), 65.8 \%$ reported having one live birth, $23.7 \%$ had two, and $10.5 \%$ had more than two. Two respondents reported that they had given birth to one child but that the child was no longer living.

Knowledge of family planning is quite low: among all respondents, few know about condoms (18.3\%) and the pill (39.5\%) (Table 4). Knowledge of HIV is higher: $61.5 \%$ of girls have heard of HIV, but only $29.3 \%$ (18.0\% of girls overall) know that using a condom every time during sex decreases the risk of acquiring HIV.

Among ever-married girls, $50.7 \%$ reported that their husband was aware of their decision to use/not use family planning. We asked ever-married and ever-pregnant girls whether they were currently using family planning and found that $24.3 \%$ reported using family planning (note that this is based on fewer than 10 cases). For the majority of married respondents their reasons for not using family planning were not due to husband refusal: $85.9 \%$ reported that their husband had never tried to prevent them from using a family planning method. Research suggests that youth-friendly health facilities that offer nonjudgmental clinic staff, welcome men and boys, and promote their services for youth within a community can increase health-service use levels among adolescents (Mmari and Magnani 2003). Low usage of family planning may be due in part to access to adolescent-friendly health facilities. Among all respondents, only $2.0 \%$ reported that the community had a youth-friendly health facility and only $41.7 \%$ of those $(0.8 \%$ of all respondents) reported ever visiting a youth-friendly health facility in their community.
18.0\%: Girls know about HIV and know that using a condom every time they have sex can reduce their risk of acquiring HIV.

2.0\%: Girls report their community has a youth-friendly health clinic.

$0.6 \%$ : Never-married girls report ever being pregnant. 
TABLE 4. Key reproductive health indicators, by state

\begin{tabular}{|c|c|c|c|}
\hline & Tillaberi & Maradi & Total \\
\hline $\begin{array}{l}\text { Ever pregnant, among ever } \\
\text { married (\%) }\end{array}$ & 35.8 & 13.6 & 25.6 \\
\hline $\begin{array}{l}\text { Ever pregnant, among never } \\
\text { married (\%) }\end{array}$ & $(0.7)$ & $(0.0)$ & $(0.6)$ \\
\hline $\begin{array}{l}\text { Use family planning, among ever } \\
\text { married }\end{array}$ & (32.1) & $(0.0)$ & $(24.3)$ \\
\hline Have heard of condoms (\%) & 18.2 & 18.6 & 18.3 \\
\hline $\begin{array}{l}\text { Do not know that each condom } \\
\text { should only be used once to be } \\
\text { effective (\%) }\end{array}$ & 54.8 & 70.3 & 60.0 \\
\hline Have heard of the pill (\%) & 42.1 & 34.2 & 39.5 \\
\hline $\begin{array}{l}\text { Do not know that the pill must } \\
\text { be taken daily to be effective (\%) }\end{array}$ & 74.6 & 58.8 & 70.0 \\
\hline $\begin{array}{l}\text { Know about HIV and know that } \\
\text { using a condom every time } \\
\text { reduces risk (\%) }\end{array}$ & 19.9 & 14.1 & 18.0 \\
\hline $\begin{array}{l}\text { Report their community has a } \\
\text { youth-friendly health facility (\%) }\end{array}$ & $(1.5)$ & $(3.0)$ & $(2.0)$ \\
\hline
\end{tabular}

Figures in parentheses are based on fewer than 10 cases.

${ }^{a}$ Ns differ by question due to skip patterns for sexual history questions (15 and older). 


\section{Education}

Increasing access to and engagement in formal education is an important component of the MTBA program. We examined enrollment in school, number of years of education completed, self-reported literacy, and assessed literacy and numeracy skills. Figure 5 shows the proportion of girls not enrolled in school by age, suggesting that overall enrollment rates start to drop after age 12 in Maradi and 13 in Tillaberi, culminating in $82.0 \%$ of 19 -year-olds not enrolled in school. Examining these data by region, we find that the proportion not enrolled in school is consistently higher in Maradi compared to Tillaberi (overall $48.6 \%$ of those in Tillaberi are not in school compared to $85.4 \%$ in Maradi). In Maradi, no girls in our sample were in school after age 16, and by age $14,84.4 \%$ were not in school. This may be due to the availability of secondary schools in these areas or in part to the anticipation of the onset of puberty; the mean age at which menstruation started was 14.4, among those who had already begun menstruating. We also looked at years of school completed among those ever enrolled in school, comparing regions. In Tillaberi, the mean number of years of education completed was 5.2 while in Maradi it only was 3.9 years. Table 5 shows key education variables by region.

\section{8\%: Girls aged 12-19 currently enrolled in school.}

\section{$3.5 \%$ : Girls report being harassed in school.}

4.9: Mean years of education completed (among ever attended school).

Table 6 examines key education variables by marital history showing that never-married girls are far more likely to have ever attended school (71.9\%) compared to their ever-married peers (40.2\%) and are less likely to be illiterate $(43.7 \%$ compared to $77.9 \%)$.

In addition to experience with schooling, we also examined literacy by asking respondents whether they could read, write, do both, or do neither (Table 7). Self-reported literacy is higher in Tillaberi compared to Maradi. In Tillaberi, $44.1 \%$ of respondents report being able to read and write compared to $14.1 \%$ of those in Maradi. We examined this by education level and found that among those currently enrolled in school, 73.3\% in Tillaberi and 55.2\% in Maradi report being able to read and write. Among those not currently enrolled in school, only $13.3 \%$ in Tillaberi and $7.1 \%$

FIGURE 5: Proportion not enrolled in school, by age $(n=365)$

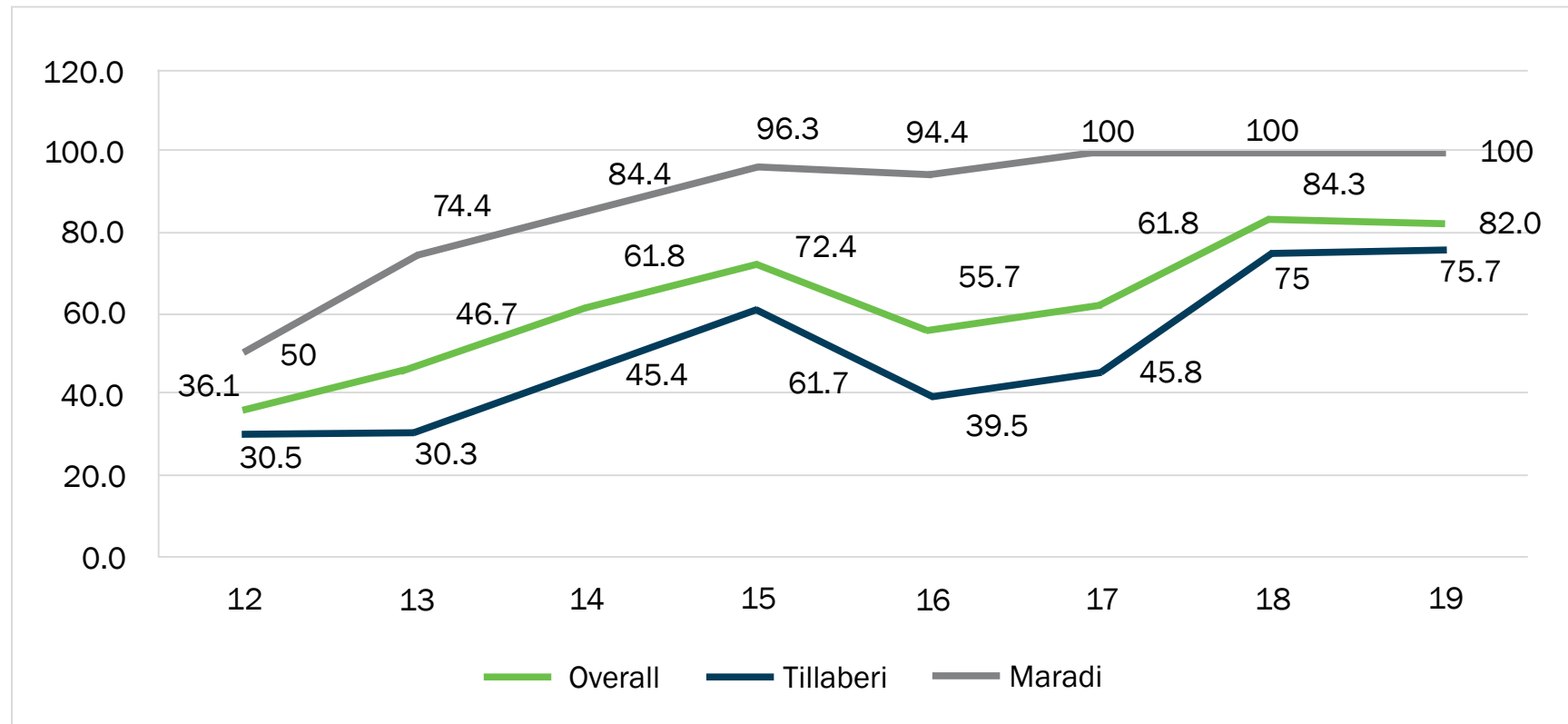


TABLE 5. Key education variables, girls aged $12-19(n=600)$, by region

\begin{tabular}{|l|c|c|c|}
\hline & Tillaberi & Maradi & Overall \\
\hline & $\mathrm{N}=401$ & 64.8 & 3800 \\
\hline Never attended school (\%) & 24.7 & 85.4 & 60.8 \\
\hline Not currently enrolled in school (\%) & 48.6 & 79.4 & 54.5 \\
\hline Cannot read or write (overall sample) (\%) & 42.1 & 27.6 & 12.8 \\
\hline $\begin{array}{l}\text { Cannot read or write (among currently } \\
\text { attending school) (\%) }\end{array}$ & 10.7 & \multirow{2}{*}{19} \\
\hline
\end{tabular}

TABLE 6. Key education variables, by marital history, girls aged 12-19 ( $n=599)$

\begin{tabular}{|l|c|c|}
\hline & Ever married & Never married \\
\hline & $\mathrm{N}=189$ & $\mathrm{~N}=410$ \\
\hline Ever attended school (\%) & 40.2 & 41.9 \\
\hline Not currently enrolled in school (\%) & 96.8 & 5.1 \\
\hline $\begin{array}{l}\text { Years of school completed (among ever } \\
\text { attended school) (mean) }\end{array}$ & 4.4 & 43.7 \\
\hline Cannot read or write (overall sample) (\%) & 77.9 & 12.2 \\
\hline $\begin{array}{l}\text { Cannot read or write (among currently } \\
\text { attending school) (\%) }\end{array}$ & $33.3^{\mathrm{a}}$ & \multirow{2}{*}{1} \\
\hline
\end{tabular}

a Indicates proportion based on fewer than 10 cases.

of those in Maradi report being able to read and write. In addition to self-reported data, we also conducted a literacy assessment, asking respondents to read two sentences in French. In Tillaberi, 89.2\% of respondents and in Maradi $95.9 \%$ could not read either sentence, while $6.7 \%$ (in Tillaberi) and 3.5\% (in Maradi) could read at least one of the sentences. We examined this by school enrollment and found that among those currently enrolled in school, $35.7 \%$ could read both sentences, $26.8 \%$ could read one, and $37.4 \%$ could not read either sentence. These findings suggest that school quality is likely very low as more than a third of in-school girls cannot read in French, the language of instruction in schools. ${ }^{8}$

We also asked about education aspirations to explore what girls want in terms of educational opportunities. Among those who had ever gone to school $(n=371)$ the most common response was "completing vocational school" at $22.4 \%$, with completing the third year (17.2\%) and completing the terminal (14.6\%) also common.

\section{KEY FINDING}

$540 \%$ Girls who cannot read or write (overall sample)

We also asked girls how far their parents would like them to go in school. The most common response was "up to the level I want" at $29.6 \%$, with completing vocational school (14.0\%) and completing the third year (12.1\%) also common. A substantial number of girls $(n=58,15.6 \%)$ did not know how far their parents would like them to go in school.

\footnotetext{
${ }^{8}$ Although French is the official language in schools, a World Bank report notes that some early grade schools (grades 1-3) teach in the local language only, and some questions split time between French and Arabic equally (World Bank 2005). Since French is the official language in schools, we used French in our literacy assessments.
} 
TABLE 7. Self-reported and assessed literacy, by state and school status $(n=599)$

\begin{tabular}{|c|c|c|c|c|c|c|c|}
\hline & \multicolumn{3}{|c|}{ Tillaberi } & \multicolumn{3}{|c|}{ Maradi } & \multirow{3}{*}{ Total } \\
\hline & \multirow{2}{*}{ Overall } & \multicolumn{2}{|c|}{ By school status } & \multirow{2}{*}{ Overall } & \multicolumn{2}{|c|}{ By school status } & \\
\hline & & Not enrolled & Enrolled & & Not enrolled & Enrolled & \\
\hline $\begin{array}{l}\text { Can read and } \\
\text { write (self- } \\
\text { reported) }\end{array}$ & 44.1 & 13.3 & 73.3 & 14.1 & 7.1 & 55.2 & 45.5 \\
\hline $\begin{array}{l}\text { Can read one (of } \\
\text { two) sentences in } \\
\text { French }\end{array}$ & 17.5 & 6.7 & 27.7 & 6.0 & $(3.5)$ & $(20.7)$ & 13.7 \\
\hline $\begin{array}{l}\text { Can read both } \\
\text { sentences in } \\
\text { French }\end{array}$ & 22.4 & $(4.1)$ & 39.8 & $(1.5)$ & $(0.6)$ & $(6.9)$ & 15.5 \\
\hline
\end{tabular}

Figures in parentheses are based on fewer than 10 cases. 


\section{Livelihoods}

Research suggests that poverty and limited opportunities for income generation are key factors influencing early marriage in some settings. We asked respondents about their experience working for income and the kinds of work they have done. The data suggest that few girls are engaged in income-generating activities: $15.8 \%$ of respondents aged 12-19 reported ever working to earn money (Table 8). Among older respondents (aged 15-19) the proportion was the same (15.8\%). For those who reported ever working $(n=95)$, we also asked about whether respondents were currently involved in income-generating activities and found that $47.4 \%$ were currently working, with a higher proportion in Tillaberi currently working (58.7\%) compared to Maradi (25.0\%). We did not find an association between ever working and either marital or schooling status.

Among those currently working, we asked about occupation, hours worked, and monthly income received. The most common occupation was trader (68.9\%), which was similar in both Tillaberi (67.6\%) and Maradi (75.0\%). ${ }^{9}$ Among those working for income, the mean amount earned per month was 10,905 CFA (about US\$18).

We also asked respondents about other sources of revenue outside of work. Very few respondents $(6.7 \%)$ reported any income source outside of work. Among those who reported additional sources of revenue $(n=3)$ all reported the source as a close family member or husband.

\section{8\%: Girls 12-19 ever worked to earn money.}

47.4\%: Girls currently involved in incomegenerating activities (among girls 12-19 who ever worked).

\section{$11.2 \%$ : Girls report saving money for the} future.

Overall, $11.2 \%$ of the baseline sample reported saving money for the future. At home was the most common location for saving (52.2\%) followed by with a relative (31.3\%) and in an informal savings group (14.9\%). No respondents reported saving in a bank. The most common reasons for saving were for clothing, shoes, and other personal items (73.1\%), sharing with family and friends (17.9\%), emergency (19.4\%), and other (13.4\%).

Exploring data on livelihoods among adolescent girls living in Tillaberi and Maradi shows that few girls engage in livelihoods activities, and among those that do the earnings reported by girls are low, although not insignificant in a country where the per capita GNI is $\$ 390$ (World Bank 2017).

TABLE 8. Key livelihoods indicators, by state

\begin{tabular}{|l|c|c|c|}
\hline & Tillaberi & Maradi & Overall \\
\hline Ever worked to earn money (12-19) (\%) & 15.7 & 16.1 & 15.8 \\
\hline Ever worked to earn money (15-19) (\%) & 15.1 & 17.3 & 15.8 \\
\hline $\begin{array}{l}\text { Currently working to earn money (among } \\
\text { ever worked) (\%) }\end{array}$ & 58.7 & 25.0 & 47.4 \\
\hline $\begin{array}{l}\text { Report occupation as trader (among } \\
\text { currently working) (\%) }\end{array}$ & 67.6 & $(75.0)$ & 68.9 \\
\hline $\begin{array}{l}\text { Mean income per month (among } \\
\text { currently working) [CFA (USD)] }\end{array}$ & $\begin{array}{c}10,645 \text { CFA } \\
(\$ 18.24)\end{array}$ & $\begin{array}{c}12,111 \text { CFA } \\
(\$ 20.75)\end{array}$ & $\begin{array}{c}10,905 \text { CFA } \\
(\$ 18.68)\end{array}$ \\
\hline Report saving for the future (\%) & 9.7 & 14.1 & 11.2 \\
\hline
\end{tabular}

\footnotetext{
${ }^{9}$ Note that only 8 girls in Maradi reported currently working for income.
} 


\section{Adolescent Social Life}

Interventions to address early marriage should aim to understand the social context in which girls live, including an understanding of the prevailing gender norms and attitudes toward women. To better understand the social context in these communities, we examined gender attitudes, asking respondents questions related to girls' rights, girls' standing in their family compared to boys, attitudes toward violence against women, and notions of male masculinity. We examined responses to these questions by marital status, assuming that ever-married girls may have a different perspective than their nonmarried peers, as well as by region. Results are shown in Table 9.
Overall, we found that both ever-married and never-married respondents in Niger had more gender-equitable attitudes than we would have predicted, based on the high rates of early marriage in Niger. For example, only $40.3 \%$ felt that girls did not have a right to refuse an arranged marriage and only $21.9 \%$ agreed that there are times when a woman deserves to be beaten. However, there is still considerable work to be done, particularly among ever-married girls: 98.9\% of ever-married girls (and $95.7 \%$ of never-married) agreed that a woman should always obey her husband, $55.1 \%$ (ever- and never-married) agreed that a woman should tolerate violence to keep her family together, and

TABLE 9. Gender-equitable attitudes, by state and marital status

\begin{tabular}{|c|c|c|c|c|}
\hline & \multicolumn{4}{|c|}{ Percent agree/strongly agree } \\
\hline & \multicolumn{2}{|c|}{ Tillaberi } & \multicolumn{2}{|c|}{ Maradi } \\
\hline & Ever married & Never married & Ever married & Never married \\
\hline & $N=106$ & $N=295$ & $N=84$ & $N=115$ \\
\hline \multicolumn{5}{|l|}{ Marriage decisions } \\
\hline $\begin{array}{l}\text { Boys do not have the right to refuse an arranged } \\
\text { marriage }\end{array}$ & 52.1 & $32.5 * *$ & 50.0 & 45.4 \\
\hline $\begin{array}{l}\text { Girls do not have the right to refuse an arranged } \\
\text { marriage }\end{array}$ & 51.5 & $32.3 *$ & 46.8 & 39.8 \\
\hline \multicolumn{5}{|l|}{ Gender roles } \\
\hline $\begin{array}{l}\text { The most important role of a woman is to take care } \\
\text { of the household and cooking for her family }\end{array}$ & 84.0 & $64.9 * * *$ & 92.8 & 88.5 \\
\hline $\begin{array}{l}\text { It is the woman's responsibility to avoid getting } \\
\text { pregnant }\end{array}$ & 48.8 & 55.9 & 52.2 & 53.7 \\
\hline $\begin{array}{l}\text { If someone insults a man, he should defend his } \\
\text { reputation, by force as necessary }\end{array}$ & 50.0 & 44.4 & 45.2 & 44.3 \\
\hline A woman should always obey her husband & 98.1 & 96.2 & 100.0 & 94.7 \\
\hline $\begin{array}{l}\text { A woman should have the right to divorce her } \\
\text { husband }\end{array}$ & 46.8 & 32.5 & 7.4 & 8.4 \\
\hline \multicolumn{5}{|l|}{ Violence acceptance } \\
\hline $\begin{array}{l}\text { There are times when a woman deserves to be } \\
\text { beaten }\end{array}$ & 18.1 & 20.4 & 21.9 & 29.2 \\
\hline $\begin{array}{l}\text { A woman should tolerate violence in order to keep } \\
\text { her family together }\end{array}$ & 46.9 & 51.8 & 65.0 & 62.9 \\
\hline \multicolumn{5}{|l|}{ Violence acceptance } \\
\hline $\begin{array}{l}\text { A woman cannot refuse to have sex with her } \\
\text { husband }\end{array}$ & 67.0 & 60.9 & 46.8 & 47.6 \\
\hline $\begin{array}{l}\text { When a woman is raped, it is usually her fault for } \\
\text { being in that situation }\end{array}$ & 6.0 & 9.2 & 42.6 & 47.4 \\
\hline
\end{tabular}

$* * * p<.001, * * p<.01, * p<.05$ denote significant differences between married and never-married respondents (within the region) accounting for cluster effects at the village level. 


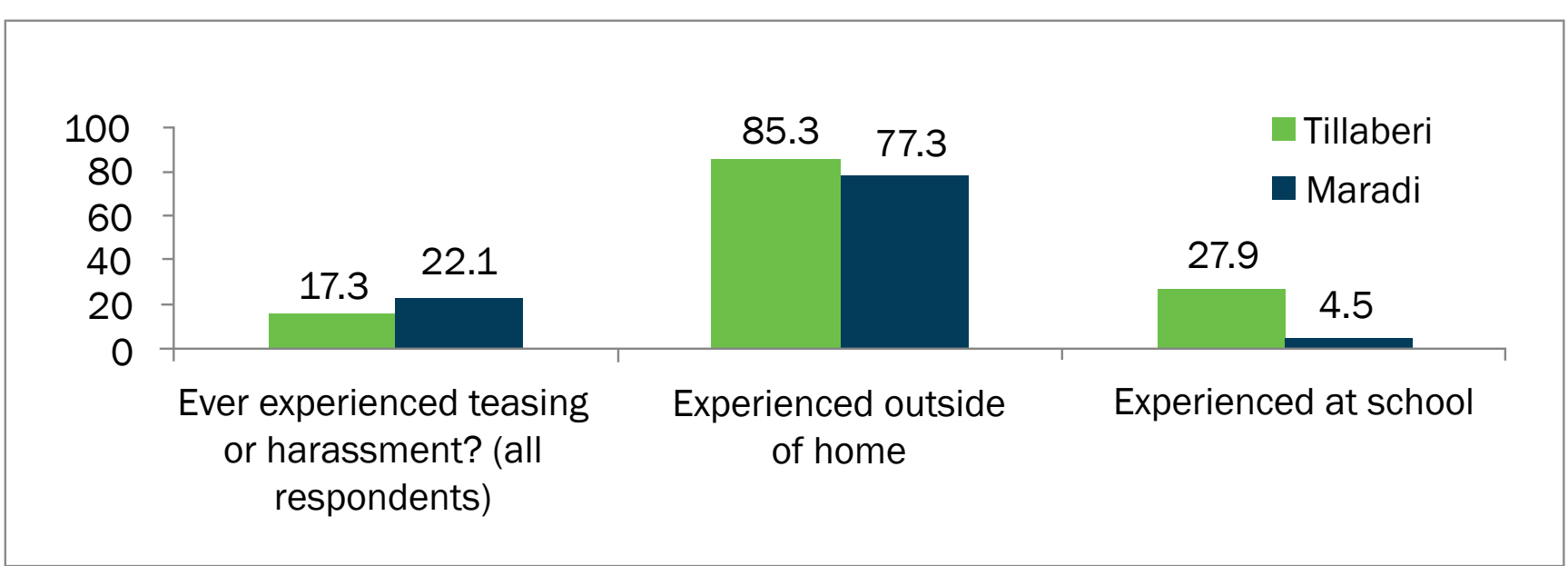

$58.1 \%$ of girls over age 15 agreed that a woman cannot refuse to have sex with her husband.

In addition to examining attitudes, we were also interested in understanding the social life of girls in these communities. We asked girls about experiences of teasing or harassment, comparing respondents in Tillaberi and Maradi. Responses to key items are shown in Figure 7. We asked girls if they had ever experienced boys or men disturbing them, calling or speaking to them rudely, or whistling or giving unwanted attention either at home or outside the home. We found that about one in five girls reported ever experiencing teasing or harassment (17.3\% in Tillaberi and $22.1 \%$ in Maradi). Among those who did, we asked specifically about whether the harassment occurred at home and/or at school: harassment was commonly experienced outside the home (85.3\% and $77.3 \%$, Tillaberi and Maradi, respectively) and less commonly experienced at school $(27.9 \%$ and $4.5 \%$, Tillaberi and Maradi, respectively). Low levels of experience of harassment at schools may be due in part to low overall levels of schooling.

We know from previous research that as girls get older their worlds shrink compared to their male peers (Hallman et al. 2015) and our findings suggest that girls in our research have limited mobility. Overall $75.2 \%$ of respondents reported that they could not go out after sunset, with significant differences by region (85.3\% in Tillaberi and $54.8 \%$ in Maradi). Most respondents (96.7\% in Tillaberi and $84.3 \%$ in Maradi) report that their parent or guardian worries about their safety.

\section{$75.5 \%$ : Girls report not being part of a club or} group.

96.8\%: Girls agree or strongly agree that a woman should always obey her husband.

55.1\%: Girls agree or strongly agree that a woman should tolerate violence to keep her family together.

The findings suggest that in these communities there are traditional gender norms around marriage and women's role within the family, although less than we would have expected. Fewer than half of girls thought that boys (41.2\%) and girls $(40.3 \%)$ had a right to refuse an arranged marriage. Even fewer (21.9\%) felt that there were times when a woman deserved to be beaten. However, $96.8 \%$ reported that a woman should always obey her husband.

There were some differences between married and never-married respondents. On some indicators those who were ever married tended to be more conservative: $87.8 \%$ of never-married girls reported that the most important role of a woman is to take care of the household and cook for her family, compared to $71.5 \%$ of never-married, and $22.5 \%$ of ever-married girls thought that when a woman is raped it is usually her fault for being in that situation, compared to $14.4 \%$ of never-married girls. 


\section{Discussion}

We examined the lives of adolescent girls, including reproductive health knowledge and experiences, education and learning outcomes, and experience with and perceptions of early marriage, with an eye toward areas where interventions could improve outcomes for girls in these communities. In surveying girls in select communities in Tillaberi and Maradi, we have a more nuanced understanding of the lives of girls in these communities and also a baseline measurement against which to measure program impact.

There are a number of interesting findings that lend themselves to further consideration as the MTBA program implementation gets under way, and we highlight a few here:

- We found low levels of schooling in both Tillaberi and Maradi: the proportion of girls never attending school was significant in each region (24.7\% in Tillaberi and $64.8 \%$ in Maradi) and by age 15 only $27.6 \%$ were in school, with far fewer in school in Maradi (3.7\%) as compared to Tillaberi (38.3\%). Marriage effectively marks the end of schooling for girls, with $3.2 \%$ of ever-married girls currently enrolled in school (no ever-married girls reported being in school in Maradi, and in Tillaberi it was only 5.7\%). Interventions that only target in-school girls will miss key populations of vulnerable girls and are too late for girls already out of school due to marriage.

- On a number of key indicators, girls in Maradi trailed those in Tillaberi. Girls in Maradi marry earlier (mean age at marriage 14.7 years compared to 15.1 in Tillaberi), are less likely to be enrolled in school (14.6\% compared to $51.4 \%$ ), have lower literacy levels (92.5\% could not read either sentence compared to $60.1 \%$ in Tillaberi), and are less likely to report currently working for income (25.0\% compared to $58.7 \%$ ). These findings are similar to data from the DHS on these indicators, although differences in the DHS data do not appear to be as stark as our findings; this may be due to site selection for the MTBA program. Although Maradi has more room for improvement as a result of the MTBA program, differences between the regions may be due to factors that are difficult to programmatically address such as cultural norms of specific ethnic groups or religions (note Maradi is $70.8 \%$ Hausa compared to $6.0 \%$ in Tillaberi). Programs may need to be tailored appropriately for each region; implementers should work closely with local partners and key informants in these communities to understand what factors contribute to early marriage in each region.

- Low levels of economic engagement for girls in Tillaberi and Maradi (15.7\% in Tillaberi and 16.1\% in Maradi report ever working) coupled with low levels of schooling (24.7\% in Tillaberi and $64.8 \%$ in Maradi never attended school) suggest that there are few options for girls outside of early marriage. In other settings we have seen that educational and/or livelihoods opportunities can provide a path for girls to delay marriage. Interventions to delay marriage should address community- and parent-level norms around opportunities for girls outside of marriage, as these are important barriers to individual-level change. Interventions may also consider ways to bolster livelihoods opportunities for girls as well as opportunities for out-of-school learning.

There are a number of limitations to consider. First, our research design did not allow for random allocation of communities, and the communities selected for inclusion in the MTBA program and research may be better off than typical communities in Tillaberi and Maradi due to the criteria used to select program sites. For example, girls in these communities may have higher levels of education, because the presence of secondary schools in these communities was a prerequisite. Another potential limitation is self-reporting bias. Our survey asks a number of sensitive questions, including questions about early marriage, which is considered illegal for girls under age 15. Girls may not have been willing to answer truthfully about early marriage and other sensitive topics, such as sexual activity. 
This baseline survey provides rich information on the lived experience of girls in these communities and highlights a number of interesting findings that programs may consider as they design and implement interventions to improve the lives of adolescent girls in Tillaberi and Maradi. Additional data collection, including qualitative data and surveys at midline and endline will provide further information and will give us a sense of how the MTBA program influences the lives of adolescent girls in these communities. 


\section{Appendix 1}

The MTBA intervention in Niger is implemented by Oxfam Novib and Save the Children and spread across 2 regions (Tillaberi and Maradi) with 3 districts in Tillaberi (Say, Torodi, Tera) and 1 district in Maradi (Tessaoua). We proposed a two arm matched comparison design in Niger using repeat cross sectional surveys. We proposed to select both intervention and comparison areas (each representing $50 \%$ of the total sample) for the baseline survey based at the village (EA) level. Based on a target sample size of 600 girls (30 clusters of 20 girls each) we estimate a minimum detectable effect size of $15 \%$ for the outcome of proportion of females aged 12-19 married at endline.
Data from the 2012 DHS provide estimates of upper and lower plausible values for early marriage in Niger. From DHS data we find that the proportion of females aged 15-19 currently married or in union in the regions of interest varies from about $58 \%$ to $72 \%$. Although the numbers for age 12-19 will likely be lower, we use these values and assume a total of 20 girls per village (EA) will be interviewed. We estimate with $n=20$ per village/EA we should have $>90 \%$ power at 30 clusters (villages/EAs).

FIGURE 1. Power calculation for sample size in Niger

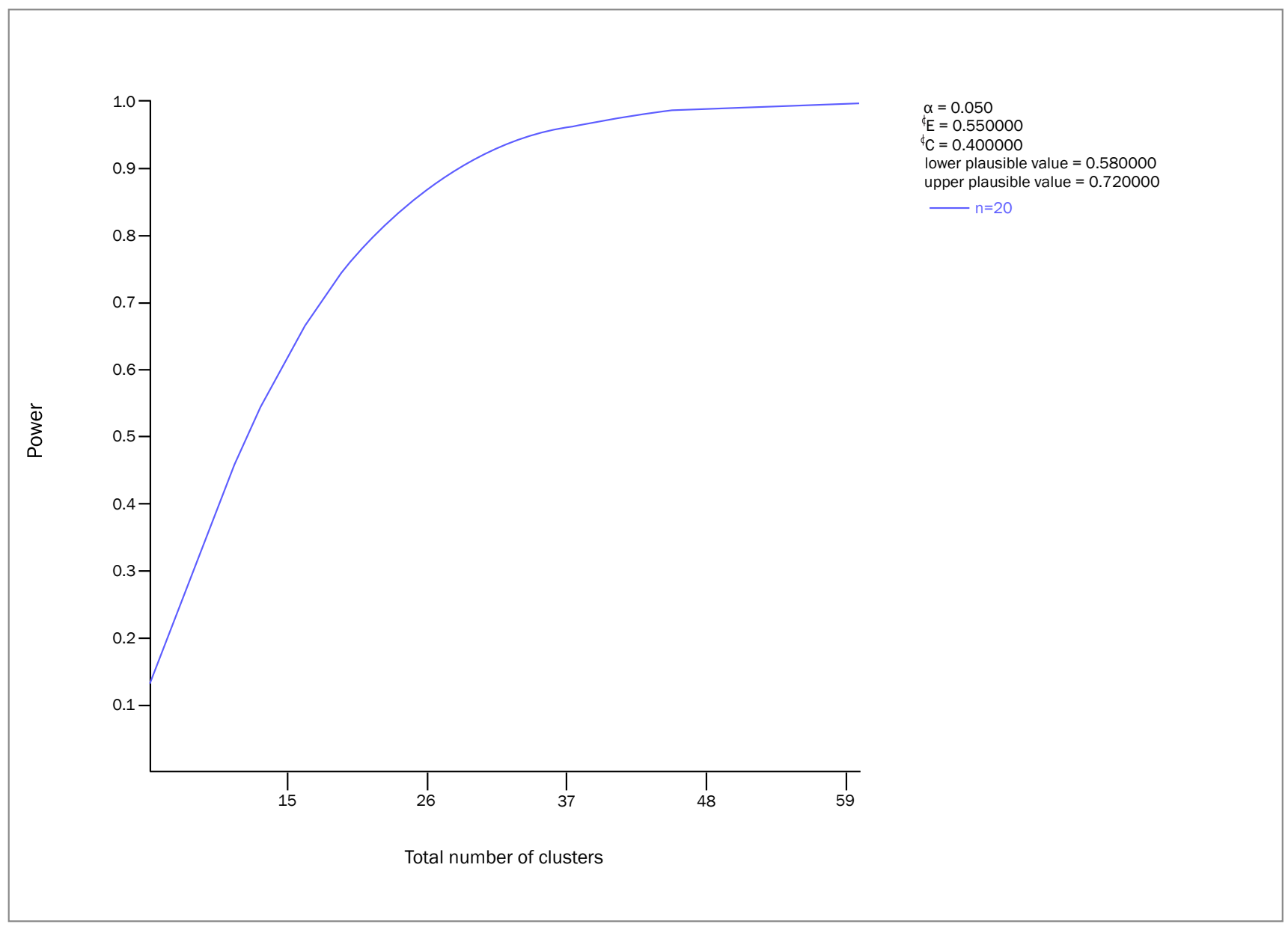




\section{Appendix 2}

FIGURE 1. Comparison of intervention and comparison areas on key indicators $(n=600)$

\begin{tabular}{|l|c|c|}
\hline & Intervention & Comparison \\
\hline & $\mathrm{N}=300$ & N700 \\
\hline Ever married (\%) & 24.7 & 24.3 \\
\hline $\begin{array}{l}\text { In polygamous union (among married) } \\
(\%)\end{array}$ & 16.4 & 8.8 \\
\hline $\begin{array}{l}\text { Mean age difference w/spouse (among } \\
\text { married) (years) }\end{array}$ & 8.9 & 46.5 \\
\hline Never attended school (\%) & 29.7 & $73.0 *$ \\
\hline Not currently enrolled in school (\%) & 49.0 & $64.0 *$ \\
\hline Cannot read or write (\%) & 45.0 & 4.3 \\
\hline Is non-Muslim (\%) & 12.3 & 26.3 \\
\hline Lowest wealth quintile (\%) & 17.0 & \multicolumn{2}{|c|}{} \\
\hline
\end{tabular}

$* * * p<.001, * * p<.01, * p<.05$. 


\section{References}

Cellule de Planification et de Statistique (CPS/SSDSPF), Institut National de la Statistique (INSTAT/MPATP), INFO-STAT, et ICF International, 2014. Enquête Démographique et de Santé au Mali 2012-2013. Rockville, Maryland: CPS, INSTAT, INFO-STAT, et ICF International.

Ensminger, J, and J. Knight. 1997. "Changing social norms: Common property, bridewealth, and clan exogamy." Current Anthropology 38(1): 1-24.

Fenn, N.S, J. Edmeades, H. Lantos, and O. Onovo. 2015. Child marriage, adolescent pregnancy, and family formation in West and Central Africa: Patterns, trends and drivers of change. ICRW and UNICEF.

Hallman, K., N, Kenworthy, J.A. Diers, N, Swan, and B. Devnarain. 2015. "The shrinking world of girls at puberty: Violence and genderdivergent access to the public sphere among adolescents in South Africa." Global Public Health 10(3): 279-295.

Malhotra, A., A. Warner, A. McGonagle, and S. Lee-Rife. 2011. Solutions to End Child Marriage: What the Evidence Shows.

Washington, DC: ICRW

Mathur, S., M. Greene, and A. Malhotra. 2003. Too Young to Wed: The Lives, Rights, and Health of Young Married Girls. Washington, DC: ICRW.

Mmari, K.N. and R.J. Magnani. 2003. "Does making clinic-based reproductive health services more youth-friendly increase service use by adolescents? Evidence from Lusaka, Zambia." Journal of Adolescent Health 33(4): 259-270.

United Nations Children's Fund (UNICEF). 2011. State of the World's Children 2011: Adolescence, An age of Opportunity. New York: UNICEF.

Walker, J.A. 2012. "Early marriage in Africa-Trends, harmful effects, and interventions." African Journal of Reproductive Health 16(2): 231-240.

World Bank. 2005. Project Performance Assessment Report: Niger First Education Project. Report Number 31657. http://documents. worldbank.org/curated/en/627131468775532838/pdf/31657. pdf.

World Bank. 2017. Data Bank: Niger. http://data.worldbank.org/ country/niger. 